\title{
Age related changes in the non-collagenous components of the extracellular matrix of the human lamina cribrosa
}

\author{
Julie Albon, Wojciech S S Karwatowski, David L Easty, Trevor J Sims, Victor C Duance
}

Department of

Optometry and Vision

Science, Cardiff

University

J Albon

Department of Ophthalmology, Leicester Royal Infirmary, Leicester W S S Karwatowski

Department of Ophthalmology, Bristol Eye Hospital, Bristol

D L Easty

Collagen Research Group, University of Bristol, Langford, Bristol

T J Sims

School of Biosciences, Cardiff University V C Duance

Correspondence to: Dr Julie Albon, Department of Optometry and Vision Science, Cardiff University, Redwood Building, King Edward VII Avenue, PO Box 905, Cardiff CF1 3XS

Accepted for publication 1 October 1999

\begin{abstract}
Aims-To investigate age related alterations in the non-collagenous components of the human lamina cribrosa.

Methods-Fibronectin, elastin, and glial fibrillary acidic protein (GFAP) staining were assessed in young and old laminae cribrosae. An age range ( 7 days to 96 years) of human laminae cribrosae were analysed for lipid content $(n=9)$, cellularity $(n=28)$, total sulphated glycosaminoglycans $(n=28)$, elastin content $(n=9)$, and water content $(n=56)$, using chloroform-methanol extraction, fluorimetry, the dimethylmethylene blue assay, and ion exchange chromatography, respectively.

Results-Qualitatively, an increase in elastin and a decrease in fibronectin and GFAP were demonstrated when young tissue was compared with the elderly. Biochemical analysis of the ageing human lamina cribrosa demonstrated that elastin content increased from $8 \%$ to $28 \%$ dry tissue weight, total sulphated glycosaminoglycans decreased, and lipid content decreased from $45 \%$ to $25 \%$. There were no significant changes in total cellularity or water content.

Conclusion-These alterations in composition may be indicative of the metabolic state of the lamina cribrosa as it ages, and may contribute to changes in mechanical integrity. Such changes may be implicated in the susceptibility of the elderly lamina cribrosa and also its response to glaucomatous optic neuropathy.

(Br F Ophthalmol 2000;84:311-317)
\end{abstract}

Chronic open angle glaucoma (COAG) is an optic neuropathy, often associated with a raised IOP, characterised by retinal ganglion cell death, optic disc cupping, and a characteristic pattern of visual field loss. Whether genetically or environmentally determined, the causes of COAG appear to be multifactorial. ${ }^{1}$ Theories as to the mechanisms of axonal damage in glaucoma include direct and indirect effects of intraocular pressure and a vasogenic cause. Evidence suggests a significant link between raised IOP and the development of glaucomatous optic nerve damage. ${ }^{2}$

Changes in the lamina cribrosa in COAG include compression of the cribriform plates, posterior rotation of the peripheral lamina, and elongation of the pores. Regional differences in architecture of the lamina cribrosa-namely, the larger pore size and sparser connective tissue of the superior and inferior regions, ${ }^{34}$ appear to correlate with the development of inferior and superior arcuate field loss in glaucoma, and relative preservation of nasal and temporal fibres, which represent temporal and central field loss respectively. ${ }^{5}$ Thus, the structure of the lamina cribrosa appears particularly relevant to glaucomatous optic nerve fibre damage.

The human lamina cribrosa consists of a lattice-like arrangement of connective tissue sheets called cribriform plates which form channels through which the retinal ganglion cell axons pass into the optic nerve proper. Immunohistochemical and electron microscopy studies of connective tissue components in normal, ${ }^{67}$ ageing, ${ }^{89}$ and glaucomatous eyes ${ }^{10-15}$ have identified various collagen types, elastin, proteoglycans, and glycoproteins in the lamina cribrosa. However, few studies have focused on the quantitative analysis of these components or how they vary with age.

We have previously quantified changes in the collagenous matrix of the ageing lamina cribrosa-namely, a decrease in percentage type III collagen relative to type I collagen, and an increase in total collagen content and the collagen cross link pentosidine. ${ }^{16}$ However, quantitative analysis of non-collagenous components has not previously been performed. Other investigators have described the distribution of proteoglycans, elastin, and glycoproteins both in monkey and human optic nerve heads by ultrastructural and immunohistochemical techniques, and qualitatively described age related alterations of glycosaminoglycans $^{13}{ }^{14}$ and elastin. ${ }^{8}$

Since age is a significant risk factor in COAG, and the structure of the human lamina cribrosa has an important role in the susceptibility of eyes to glaucomatous optic neuropathy, the aim of this present investigation was to identify changes in the non-collagenous components of the ageing lamina cribrosa which may influence its physical and functional properties.

\section{Materials and methods}

SOURCE OF TISSUE

Human cadaver eyes, encompassing an age range from 7 days to 96 years, were collected within 48 hours of death. All eyes were received from the corneal transplant service eye bank at Bristol Eye Hospital, after corneas had been removed for transplantation.

INDIRECT IMMUNOFLUORESCENCE

Optic nerves, aged between 15 and 86 years, were rapidly frozen in liquid nitrogen cooled 
isopentane and embedded in Tissue-Tek. Sections $8 \mu \mathrm{m}$ thick at the level of the lamina cribrosa were cut using a Bright cryostat. Sections were incubated for 2 hours with primary antibodies (Sigma) optimally diluted in phosphate buffered saline (PBS). Antibodies included monoclonal mouse ascites with specificity for elastin ( 1 in 5000 dilution) or glial fibrillary acidic protein ( 1 in 400 dilution) and a rabbit polyclonal antibody with specificity for cellular fibronectin (1 in 400 dilution). Control sections were incubated for 2 hours in rabbit non-immune serum or a monoclonal antibody against titin ( 1 in 400 dilution), an antigen known to be absent in the lamina cribrosa. After washing in PBS (three times), the sections were incubated for 2 hours with appropriate secondary fluorescein conjugated antibodies (Sigma), which had been adsorbed against human serum proteins. Following extensive washing in PBS, the sections were mounted in Citifluor (Agar Ltd) and viewed using a Leitz Dialux microscope with epifluorescence.

\section{BIOCHEMICAL ANALYSES}

Sample preparation

All laminae cribrosae were dissected as previously described, ${ }^{16}$ (56 samples were dissected under PBS pH 7.4, blotted on filter paper and wet weights recorded) and freeze dried for 24 hours. Each lamina cribrosa was then delipidated for 48 hours in two changes of 3:1 chloroform:methanol and freeze dried again. Dry weights were recorded after each lyophilisation.

Water content, total sulphated glycosaminoglycans and DNA content

Fifty six laminae cribrosae from 28 donors were used in these analyses.

Water content-Percentage water content was calculated as:

$\frac{\text { wet weight }- \text { dry weight }}{\text { wet weight }} \times 100 \%$

Papain digestion - Left and right laminae cribrosae from the same donor were paired and digested in $500 \mu 1$ papain digestion buffer (sterile PBS containing $5 \mathrm{mM}$ cysteine hydrochloride, 5 mM EDTA) pH 6.0 containing 300 $\mu \mathrm{g} / \mathrm{ml}$ papain, in a water bath, at $60^{\circ} \mathrm{C}$, for 48 hours. After digestion, a $50 \mu \mathrm{l}$ aliquot was analysed for hydroxyproline as described by Bannister and Burns. ${ }^{17}$ The remainder was analysed for DNA and total sulphated glycosaminoglycans content.

DNA analysis - Cellularity of the lamina cribrosa was assessed using a modified method of Kim et al. ${ }^{18}{ }^{19} \mathrm{~A}$ sample of $100 \mu \mathrm{l}$ of each papain digest was diluted to $2 \mathrm{ml}$ using $0.1 \mu \mathrm{g} / \mathrm{ml}$ Hoechst 33258 in dye buffer $(10 \mathrm{mM}$ TRIS, $1 \mathrm{mM}$ EDTA, $0.1 \mathrm{mM} \mathrm{NaCl}, \mathrm{pH} \mathrm{7.4)}$. This working dye solution was made immediately before use by dilution of a $1 \mathrm{mg} / \mathrm{ml}$ stock solution in distilled water, which was kept in an amber bottle at $4^{\circ} \mathrm{C}$. A Perkin-Elmer fluorimeter was zeroed using $100 \mu \mathrm{l}$ papain digestion buffer in dye buffer, and the DNA content of each sample was read at excitation/emission wavelength $348 \mathrm{~nm} / 457 \mathrm{~nm}$. Readings of background tissue fluorescence were measured by repeating the analysis using $100 \mu \mathrm{l}$ of sample in dye buffer (minus the Hoechst reagent) and subtracted from the original values. DNA content of each sample was calculated from a standard curve, prepared using standards ranging in concentration from $0-10 \mu \mathrm{g} / \mathrm{ml}$ calf thymus DNA.

Dimethylmethylene blue assay - Sulphated glycosaminoglycans were quantitated using a modification of the dimethylmethylene blue assay, at a $\mathrm{pH}$ and salt concentration, whereby DNA, RNA, and hyaluronic acid did not interfere in the analysis. ${ }^{20}$ A sample of $20 \mu \mathrm{l}$ of each papain digest was pipetted in 96 well microtitre plate wells. In neighbouring wells, $20 \mu \mathrm{l}$ of each glycosaminoglycan standard (dermatan sulphate or chondroitin sulphate, Sigma), ranging from 5 to $25 \mu \mathrm{g} / \mathrm{ml}$ were included to provide a standard curve. Duplicate wells with $20 \mu \mathrm{l}$ of papain digestion buffer were added to two wells to provide blanks for the assay. A volume of $125 \mu \mathrm{l}$ of 1,9 dimethylmethylene blue dye solution pH 3.0 (3.04 g glycine, $2.37 \mathrm{~g} \mathrm{NaCl}$, $95 \mathrm{ml} 0.1 \mathrm{M} \mathrm{HCl}, 16 \mathrm{mg}$ of 1,9 dimethylmethylene blue) was added to each well and the plates were read immediately using a Titertek Multiscan automated plate reader at $540 \mathrm{~nm}$. Sample concentrations were calculated using linear regression of the standard curves.

Analysis of lipid content, elastin and elastin cross links

One hundred and eighty laminae cribrosae from 90 donors, prepared as above, were divided into nine groups of 20 laminae cribrosae within age ranges $0-9,10-19,20-29$, $30-39,40-49,50-59,60-69,70-79$, and $80-89$ years.

Lipid content-Percentage lipid content was calculated as:

$\frac{\text { dry weight }- \text { dry weight after delipidation }}{\text { dry weight }} \times 100 \%$

Elastin content-Analysis of elastin in the lamina cribrosa was carried out by the measurement of the levels of the mature elastin cross links; desmosine and isodesmosine, using the method of Sims and Bailey. ${ }^{21}$ Elastin content, calculated as a measure of the elastin cross link desmosine, is widely used for the quantification of tissue elastin content, since acid hydrolysis is the only effective method for total solubilisation of the mature elastic fibre.

Following freeze drying, each group of 20 pooled laminae cribrosae was hydrolysed in $6 \mathrm{M} \mathrm{HCl}$ at $110^{\circ} \mathrm{C}$ for 24 hours. After freeze drying, the hydrolysate was rehydrated in $1 \mathrm{ml}$ of deionised water and an aliquot was assayed for hydroxyproline. ${ }^{17}$ The remainder of the sample was diluted using 4:1 butanol:acetic acid to give a final butanol:acetic acid:water ratio of $4: 1: 1$. Cross linking amino acids in the sample were separated using a CF1 cellulose (Whatman) column as described by Sims and Bailey $^{21}$ Freeze dried eluents of the CF1 column (eluted in the polar phase) containing 

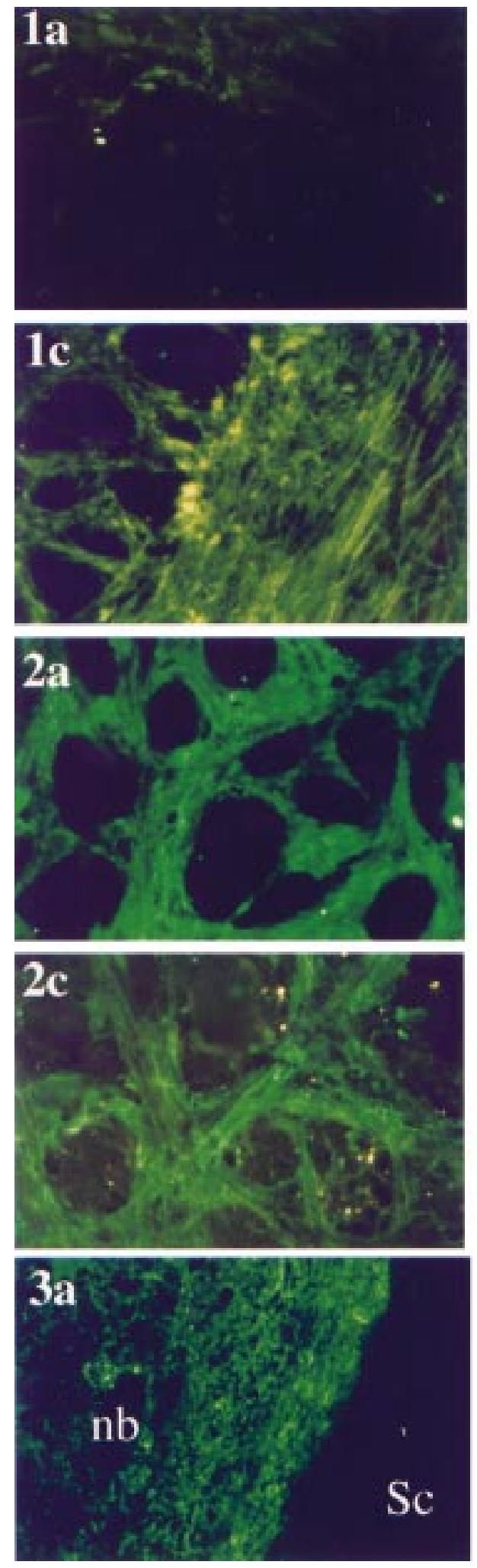

Figures 1-3(1) Cross sections of human lamina cribrosa: demonstrating the distribution of elastin staining in a 16 year old $(1 \mathrm{a}$ and $1 \mathrm{~b})$ (magnification $\times 140$ ) and an 86 year old $(1 \mathrm{c}$ and $1 \mathrm{~d})$ (magnification $\times 230)$. Positive localisation of elastin was demonstrated in (1a) the walls of the sclera and in the extrafascicular matrix of the young lamina cribrosa, and (1b) the elastic lamina of the central retinal artery; very faint staining was also observed in the walls of the central retinal vessels. (1c) Much denser staining within the sclera and extrafascicular matrix and (1d) the sheaths of the central retinal vessels was demonstrated in the 86 year old. (2) Cross sections of lamina cribrosa, immunolocalised for the glycoprotein fibronectin in tissue aged 16 years $(2 a$ and $2 b)$ and 86 years $(2 c$ and $2 d)$. Positive staining was demonstrated in the extrafascicular matrix $(2 a$ and $2 c)$ (magnification $\times 140)$ and throughout the walls of the central retinal vessels, although staining was much weaker in the 86 year old (magnification $\times 230)$. (3) Immunolocalisation of glial fibrillary acidic protein (GFAP) in cross sections of lamina cribrosa (3a) 16 year old lamina cribrosa (magnification $\times 140$ ): GFAP labelling was demonstrated at the region of insertion of the lamina cribrosa into the sclera $(\mathrm{Sc})$, and throughout the nerve fibre bundles $(n b)$. ( $3 b$ ) 78 year old lamina cribrosa (magnification $\times 140)$ : GFAP labelling followed the same distribution as that described in the young lamina, but staining was much weaker. Note the high amount of autofluorescence. 


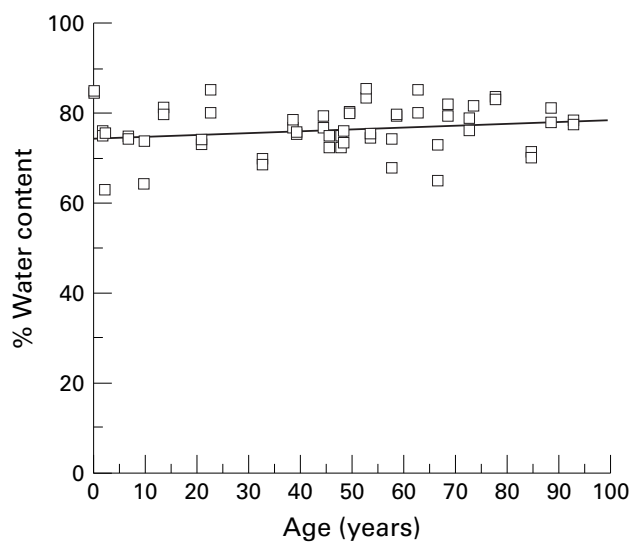

Figure 4 Water content of the ageing human lamina cribrosa. Percentage water content of the human lamina cribrosa, calculated as the difference between wet weight and dry weight after freeze drying, remained constant throughout life. Spearman's rank correlation $r_{s}=0.23$, not significant at $p=0.039, n=56$ ).

the cross linking amino acids were rehydrated in $100-200 \mu \mathrm{l} 0.2 \mathrm{M}$ sodium citrate buffer $\mathrm{pH}$ 2.2 , spun to bring sample to bottom of tube and filtered through a $0.2 \mu \mathrm{m}$ filter (Gelman Sciences, Northampton). The sample was then chromatographed on an LKB 4400 amino acid analyser, using a $270 \times 4 \mathrm{~mm}$ cation exchange column, containing Aminex A9 $11 \mu \mathrm{m}$ resin (Bio-Rad Labs, Hemel Hempstead). The amino acids were then eluted using a gradient of citrate buffer. The elastin cross links were determined as nmoles of cross link per $\mathrm{mg}$ of dry tissue weight. Assuming elastin to consist of $2.7 \%$ desmosine, ${ }^{21}$ an estimation of elastin content in the ageing lamina cribrosa was calculated.

STATISTICAL ANALYSIS

Spearman's rank correlation was used to test the tendency of values of Y (for example, total sulphated glycosaminoglycans, lipid, DNA content, etc) to increase or decrease as values of $\mathrm{X}$ (age) increase.

\section{Results}

INDIRECT IMMUNOFLUORESCENCE

Elastin

Elastin staining in the young laminae cribrosae was less intense than that in the elderly. In young laminae cribrosae, elastin was localised to the sclera, the extrafascicular matrix (Fig 1a) and the elastic lamina of the central retinal artery (Fig 1b). In the elderly, more intense staining was demonstrated throughout the extrafascicular matrix, within the sclera (Fig 1c) and the central retinal artery wall (Fig 1d).

\section{Fibronectin}

Fibronectin, absent from sclera, was localised to the cores of the cribriform plates (Fig 2a, c), and within the walls of the central retinal vessels (Fig 2b, d) with a greater intensity of staining in young tissue (Fig 2a, b).

Cellularity of lamina cribrosa

Glial fibrillary acidic protein (GFAP), a cytoskeletal cell marker specific for astrocytes, ${ }^{22}$ was demonstrated diffusely

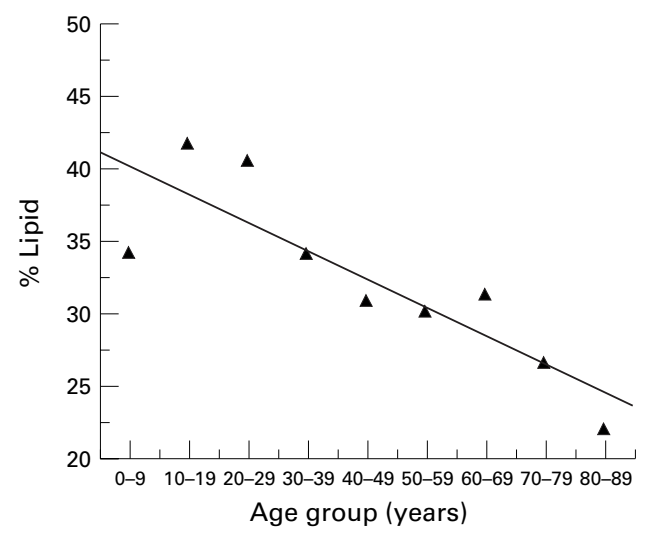

Figure 5 Lipid content in the ageing human lamina cribrosa. Percentage lipid was calculated in nine groups of laminae cribrosae aged between 1 and 89 years of age. The dry weight of each age group was measured after extraction of lipid from each group in 3:1 chloroform:methanol. The difference between this value and that of the total dry weight was expressed as a percentage of total dry tissue weight to provide a value for lipid content in each age category. Lipid content decreased linearly from $42 \%$ to $24 \%$. (Line fitted is a first order polynomial regression line $r=0.86$.)

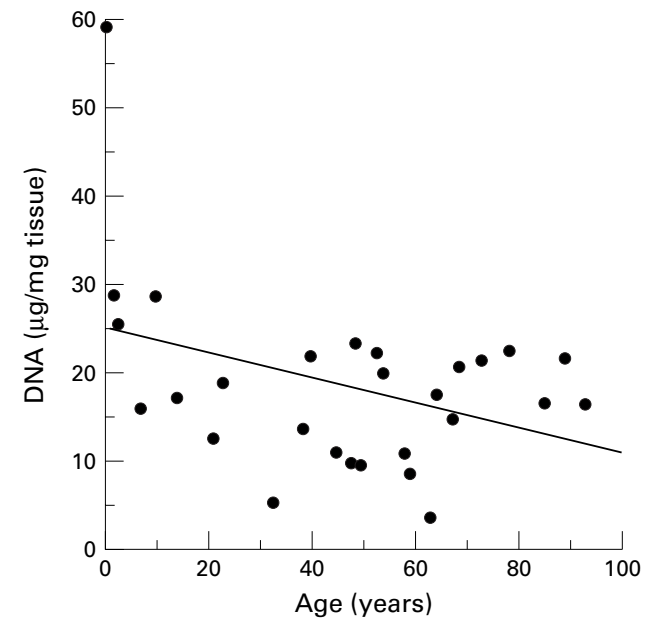

Figure 6 DNA content of human lamina cribrosa. DNA content was measured in an aliquot taken from papain digested laminae cribrosae, using Hoechst 33256.

Fluorescence of DNA-Hoechst complex was detected at excitation/emission wavelengths of $328 \mathrm{~nm} / 457 \mathrm{~nm}$ using a Perkin-Elmer fluorimeter. DNA content decreased with age, not significant at $p=0.291$. Spearman's rank correlation $r=-0.21, n=28$.

throughout the nerve fibre bundles and at the region of insertion in the young lamina cribrosa (Fig 3a). A similar distribution, but less intense GFAP staining was demonstrated in the elderly laminae cribrosae (Fig 3b), indicative of an age related decrease in number or reactivity, or a change in astrocyte cell type. ${ }^{23}$ GFAP was not present in the walls of the central retinal vessels (not shown) or sclera Fig 3a, b) consistent with the lack of astrocytes in these tissues.

Negative staining was demonstrated in control sections when using rabbit nonimmune serum or monoclonal mouse anti-titin antibody.

\section{BIOCHEMICAL ANALYSES}

Water content

Water content of the human lamina cribrosa expressed as a percentage of total wet weight of 


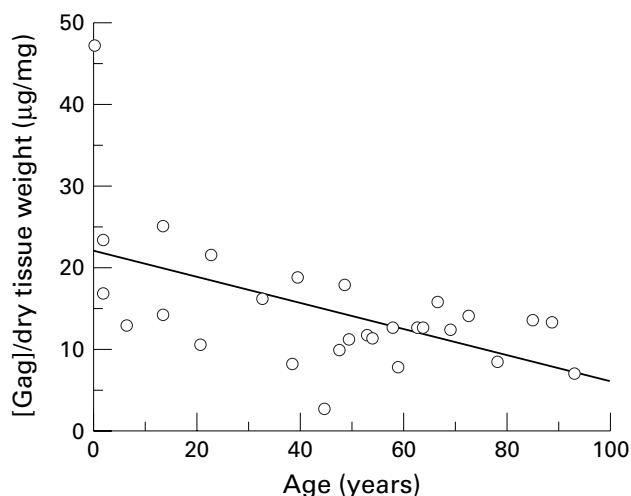

Figure 7 Sulphated glycosaminoglycans in the human lamina cribrosa. Sulphated GAGs analysis of papain digests of paired laminae cribrosae was carried out using the dimethylmethylene blue dye binding assay at an absorbance of $540 \mathrm{~nm}$. Sulphated GAGs content of the human lamina cribrosa decreased with age. (Spearman's rank correlation $r=-0.45, p=0.017$, fitted line is a regression line, $r=0.75$, $n=28$ ).

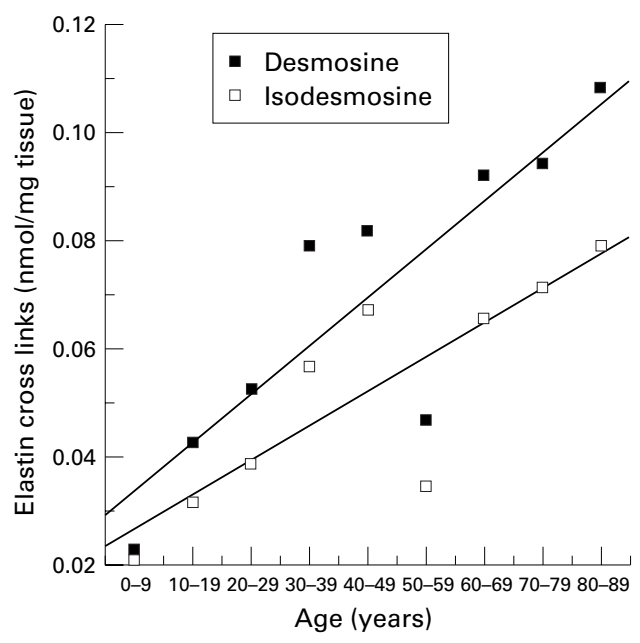

Figure 8 Elastin cross links in the human lamina cribrosa. The elastin cross links, desmosine and isodesmosine, were analysed using ion exchange chromatography, with ninhydrin detection. ${ }^{21}$ Both cross links significantly increased with age. (Lines fitted are first order polynomial regression lines with correlation coefficients $r=0.87$ and $r=0.85$, for desmosine and isodesmosine respectively.)

the tissue did not appear to alter with age (Fig $4, \mathrm{p}>0.1)$. The average water content calculated from 56 laminae cribrosae, aged between 5 months and 93 years was $78 \%$ of the total wet weight.

Lipid content

Lipid content decreased linearly from about $42 \%$ in the $0-9$ year age group to $24 \%$ in the category aged $80-89$ years (Fig 5, Spearman's rank correlation $r_{\mathrm{s}}=-0.90$, significant at $\mathrm{p}=0.001, \mathrm{n}=9)$.

\section{Cellularity}

The change in cellularity within the lamina cribrosa was expressed as the DNA content per dry tissue weight of each pair of laminae cribrosae as demonstrated in Figure 6. The DNA content appeared higher than all other values in the pair of laminae cribrosae aged 5 months. Thereafter there was a very slight but insignificant (Spearman's rank correlation $\left.r_{\mathrm{s}}=-0.21, \mathrm{p}=0.291\right)$ decrease with age.

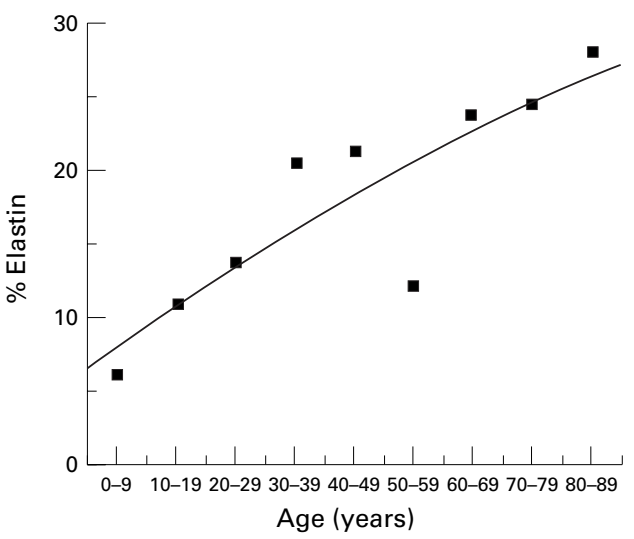

Figure 9 Elastin content of the human lamina cribrosa. Elastin content was estimated from the values of desmosine, and expressed as a percentage of total dry tissue weight. Percentage elastin increased significantly with age from $7 \%$ to $28 \%$. (Fitted line is a second order polynomial regression fit, $r=0.87$.)

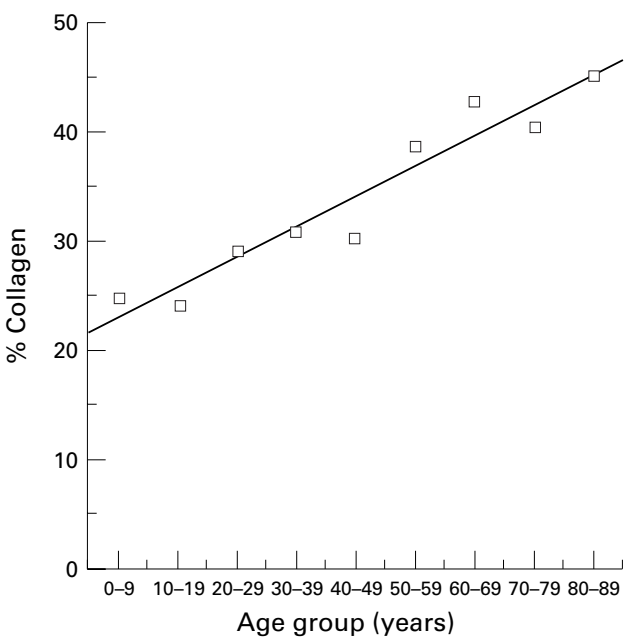

Figure 10 Collagen content of the human lamina cribrosa. Collagen content expressed as a percentage of total dry tissue weight increased from $24 \%$ to $47 \%$.

Glycosaminoglycans

Sulphated glycosaminoglycans (GAGs) in the human lamina cribrosa demonstrated a weakly significant decrease with age (Fig 7, Spearman's rank correlation $\left.r_{\mathrm{s}}=-0.45, \mathrm{p}=0.017\right)$. Wilcoxon signed rank correlation demonstrated a significant correlation between values of DNA and sulphated GAGs, correlation coefficient of 101, $\mathrm{n}=28$, significant at $\mathrm{p}<0.001$.

\section{Elastin}

Elastin cross links-The mature products of elastin cross linking-desmosine and isodesmosine increased significantly with age as indicated in Figure 8. Desmosine increased from $0.025 \mathrm{nmol} / \mathrm{mg}$ of tissue in the young to approximately $0.11 \mathrm{nmol}$ per $\mathrm{mg}$ tissue in the 80-89 year age group and isodesmosine increased from 0.02 to $0.075 \mathrm{nmol}$ per $\mathrm{mg}$ tissue. Thus, both elastin cross links increased significantly with age (Spearman's rank correlation $r_{\mathrm{s}}=0.90, \mathrm{p}=0.001$ and $r_{\mathrm{s}}=0.87, \mathrm{p}=0.002$ for desmosine and isodesmosine respectively).

Elastin content-Elastin content was calculated from values of desmosine (approximately 
$2.77 \%$ of elastin). ${ }^{21}$ Elastin values, defined in nmoles, were calculated, converted into mass and expressed as a percentage of total dry tissue weight. Percentage elastin increased significantly from $7 \%$ in the $0-9$ year group to $28 \%$ in the 80-89 year group (Fig 9, Spearman's rank correlation $r_{\mathrm{s}}=0.90$, $\mathrm{p}=0.001)$.

\section{Collagen content}

Total collagen content, as determined by hydroxyproline analysis, significantly increased from $24 \%$ in the $0-9$ years age group to $45 \%$ of total dry tissue weight in the group aged $80-89$ years (Fig 10).

\section{Discussion}

Components of the extracellular matrix of the lamina cribrosa include collagen, elastin, and sulphated GAGs. This study confirmed previously published data that collagen forms a major constituent, representing between 24\% to $45 \%$ dry tissue weight depending on age. ${ }^{21}{ }^{24}$ This investigation has demonstrated that elastin, particularly in the elderly, is also a major component, with sulphated GAGs at $1-3 \%$ dry tissue weight only a minor constituent. Any variation in the proportions of these components will affect the functional and physical properties of the lamina cribrosa as it ages. The overall increase in total connective tissue, as indicated by the cumulative increase in the major constituents: collagen and elastin, is consistent with the age related thickening of cribriform plates identified by previous investigators. $^{89}$

Elastin content increased in the human lamina cribrosa as a function of age from $7 \%$ in the $0-9$ year age group to $28 \%$ of dry tissue weight, in the 80-89 year group, consistent with increased elastin autofluorescence, ${ }^{24}$ immunofluorescent ${ }^{25}$ (also shown in this study) and immunoelectron ${ }^{26}$ labelling of elastin, previously observed, and confirmed in this study, in the human lamina cribrosa. Once laid down elastin has a very slow turnover and the cross link content remains constant. ${ }^{2127}$ No evidence of degradation of elastic fibres within the cribriform plates has been identified even in the eldest eye when examined by electron microscopy, ${ }^{26}$ implying an accumulation of elastic fibres. ${ }^{8}$ Binding of elastin to other proteins is believed to contribute to the stiffening and loss of long range elasticity associated with most ageing elastic tissues. ${ }^{27} 28$

The significant decrease in lipid content of the ageing human lamina cribrosa may be indicative of a decrease in cellular or membrane associated lipids, associated with the decrease in nerve axons in the ageing human optic nerve ${ }^{25} 29$ or the decreased cellularity suggested by the decreased GFAP labelling in the ageing lamina cribrosa.

Total sulphated GAGs concentration in the lamina cribrosa appeared to decrease with age, consistent with the age related reduction in length and diameter of cuprolinic blue positive chondroitin/dermatan sulphate and also heparan sulphate proteoglycan filaments previously observed. ${ }^{14}$
Total GAG content of the lamina cribrosa constitute between $1 \%$ and $3 \%$ of tissue dry weight. In articular cartilage, which contains GAGs as $15 \%$ of its total tissue dry weight, the large aggregating proteoglycan, aggrecan, contributes to its adaptation to withstand large compressive forces. In contrast, fibrous flexor tendon which experiences predominantly tensile forces comprises the small dermatan sulphate proteoglycan, decorin, as less than $1 \%$ dry weight. ${ }^{30}$ It is unlikely that GAGs in the lamina cribrosa affect tissue hydration or its ability to withstand the forces exerted on it by diurnal and age related fluctuations in intraocular pressure as suggested by Caparas et $a l .{ }^{13}$ Indeed no change in tissue hydration, constant at approximately $78 \%$, was observed in the ageing lamina cribrosa.

Biomechanical properties of connective tissues may be indirectly influenced by interactions of proteoglycans, including collagen fibrillogenesis, cell-cell interactions, growth factor binding, and cell regulation. ${ }^{31}$ The small dermatan/chondroitin sulphate proteoglycan decorin, localised in association with the interstitial collagens of the human lamina cribrosa, ${ }^{11}$ has a role in the regulation of collagen fibril diameters and the assembly of matrix components. $^{30}$ Biglycan, a second small dermatan/chondroitin sulphate proteoglycan, also localised to the lamina cribrosa may play a part in the development of the tissue. ${ }^{11} \mathrm{~A}$ strong correlation exists between decreasing total GAGs content and an increase in mean fibril diameters. The higher level of total sulphated GAGs content in young laminae cribrosae implies smaller collagen fibril diameters which may contribute to creep resistant properties within a tissue and therefore enhance its resilience. ${ }^{32}$ The young lamina cribrosa is able to reverse optic disc cupping in infant glaucoma, ${ }^{33}$ suggestive that the young lamina cribrosa is more resilient than adult tissue. Biomechanical studies in this laboratory have confirmed this. ${ }^{24} 34$

Previous studies have suggested a heterogeneity of astrocytes in the human optic nerve head. ${ }^{23}$ Cell culture studies have identified two cell types in the human lamina cribrosa ${ }^{35}{ }^{36}$ : the GFAP positive astrocyte and a large flat polygonal cell named lamina cribrosa cell. The latter cell type synthesises elastin, collagen types I, III, and IV, components of the cribriform plates, whereas the astrocytes synthesise type IV collagen. Astrocytes in the lamina cribrosa line basement membranes along the cribriform plates and surrounding the central retinal vessels, segregating the neural elements of the lamina cribrosa from connective tissue-that is, forming a glial limitans, as is true throughout the $\mathrm{CNS}^{37}$ GFAP labelling demonstrated astrocytes within nerve fibre bundles, making contacts with both nerve axons and other neighbouring astrocytes. $^{38}$ The intimate relation between astrocytes and with other elements in the nervous system provides metabolic support and barrier functions. ${ }^{39}$ The relevance of an apparent decrease in astrocytes with age in the lamina cribrosa is unknown. However, astro- 
cytes are important during development when the morphogenetic activity is high. As in other tissues, labelling of fibronectin indicated codistribution with collagen types I and III. ${ }^{40}{ }^{41}$ Fibronectin is important in cell matrix interactions in cell migration and proliferation. The age related decrease in fibronectin, similar to that in the dermis and peripheral nerves, may be related to a decrease in morphogenetic activity of the lamina cribrosa. ${ }^{42} 43$

In conclusion, the alterations of noncollagenous components of the extracellular matrix of the lamina cribrosa ${ }^{16}$ may contribute to an age related stiffening and reduction in resilience, described in the lamina cribrosa. ${ }^{24} 34$ GAGs or proteoglycans may indirectly influence these properties by their role in the regulation of collagen fibril diameters. Ageing of elastin results in a deficiency of functional elastic fibres and subsequent reduction in recoil properties and elasticity, generally associated with ageing elastic tissues. ${ }^{44}$ The effect of such changes on the biophysical and biomechanical properties of the ageing lamina cribrosa and its implications in the susceptibility of the lamina cribrosa to glaucomatous optic neuropathy need further investigation.

The authors would like to thank the CTS Eye Bank, Bristol Eye Hospital for the provision of eyes and Professor Allen Bailey for allowing this work to be carried out within the Muscle and Collagen Research Group in the Department of Clinical Veterinary Science at the University of Bristol, Langford. This project was supported by the Guide Dogs for the Blind Association, National Eye Research Council and the Iris Fund.

1 Fechtner RD, Weinreb RN. Mechanisms of optic nerve damage in primary open-angle glaucoma. Surv Ophthalmol 1994;39:23-42.

2 Sommer A. Intraocular pressure and glaucoma. $\mathrm{Am} \mathcal{F} \mathrm{Oph}$ thalmol 1989;107:186-8.

3 Quigley HA, Hohman RM, Addicks EM, et al. Morphological changes in the lamina cribrosa correlated with neural loss in open-angle glaucoma. Am f Ophthalmol 1983;95: loss in ope $673-91$.

4 Quigley HA, Addicks EM. Regional differences in the structure of the lamina cribrosa and their relation to glaucomatous optic nerve damage. Arch Ophthalmol 1981;99:13743.

5 Quigley HA, Addicks EM, Green WR, et al. Optic nerve damage in glaucoma: II The site of injury and susceptibility to damage. Arch Ophthalmol 1981;99:635-49.

6 Hernandez MR. Extracellular matrix molecules of the lamina cribrosa: a pressure-sensitive connective tissue. $\mathcal{F}$ Glaucoma 1993;2:50-7.

7 Goldbaum MH, Jeng S, Logemann R, et al. The extracellular matrix of the human optic nerve. Arch Ophthalmol 1989;107:1225-31.

8 Hernandez MR, Luo XX, Andrzejewska W, et al. Agerelated changes in the extracellular matrix of the human optic nerve head. Am f Ophthalmol 1989;107:476-84.

9 Morrison JC, Jerdan JA, Dorman ME, et al. Structural proteins of the neonatal and adult lamina cribrosa. Arch Ophteins of the neonatal and a
thalmol 1989;107:1220-24.

10 Hernandez MR, Ye H. Glaucoma: changes in extracellular matrix in the optic nerve head. Ann Med 1993;25:309-315.

11 Morrison JC, Johnson E. Biglycan and decorin distribution in the primate optic nerve head. Invest Ophthalmol Vis Sci 1992;33:1091.

12 Morrison JC, Rask P, Johnson EC, et al. Chondroitin sulphate proteoglycan distribution in the primate optic nerve head. Invest Ophthalmol Vis Sci 1994;35:838-45.

13 Caparas VL, Cintron C, Hernandez-Neufeld MR. Immunohistochemistry of proteoglycans in human lamina cribrosa. Am f Ophthalmol 1991;112:489-95.

14 Sawaguchi S, Yue BYJT, Fukuchi $\mathrm{T}$, et al. Age-related changes of sulphated proteoglycans in the human lamina cribrosa. Curr Eye Res 1993;12:685-692.

15 Quigley HA, Dorman-Pease ME, Brown AE. Quantitative study of collagen and elastin of the optic nerve head and sclera in human and experimental glaucoma. Curr Eye Res 1991; 10:877-88.

16 Albon J, Karwatowski WSS, Avery N, et al. Changes in the collagenous matrix of the ageing human lamina cribrosa. Br F Ophthalmol 1995;79:368-75.

17 Bannister DW, Burns AB. Adaptation of the Bergman and Loxley technique for hydroxyproline determination to the autoanalyser and its use in determining plasma hydroxyproline in the domestic fowl. Analyst 1970;95:596-600.

18 Kim Y-J, Sah RLY, Doong JYH, et al. Fluorometric assay of DNA in cartilage explants using Hoechst 33258. Anal Biochem 1988;174:168-76.

19 Labarca C, Paigen KA. A simple rapid and sensitive DNA assay procedure. Anal Biochem 1980;102:344-52.

20 Farndale RW, Buttle DJ, Barret AJ. Improved quantitation and discrimination of sulphated glycosminoglycans by use of dimethylmethylene blue. Biochim Biophys Acta 1986;883: 173-7.

21 Sims TJ, Bailey. Quantitative analysis of collagen and elastin cross-links using a single-column system. F Chromat 1992; 582:49-55.

22 Bignami A, Dahl D. Specificity of glial fibrillary acidic protein for astroglia. F Histochem Cytochem 1997;25:466-9.

23 Kobashyi S, Vidal I, Pena JD, et al. Expression of neural cell adhesion molecule (NCAM) characterises a subpopuation 20:262-73

24 Albon J. An investigation into the age-related changes in the extracellular matrix of the human lamina cribrosa. $\mathrm{PhD}$ thesis. Bristol: University of Bristol, 1995.

25 Balazsi AG, Rootman J, Drance SM, et al. The effect of age on the nerve fibre population of the human optic nerve. Am f Ophthalmol 1984;97:760-6.

26 Hernandez MR. Ultrastructural immunocytochemistry of elastin in thge human lamina cribrosa: changes in elastic fibres in chronic open-angle glaucoma. Invest Ophthalmol Vis Sci 1992;33:2891-900.

27 Robert L. Ageing of connective tissue. Mech Age Dev 1980; 14:273-82.

28 Schofield JD, Weightman B. New knowledge of connective tissue ageing. F Clin Path (Suppl) 1974;12:174-90.

29 Jonas JB, Muller-Bergh JA, Schlotzer-Schrehardt UM. Histomorphometry of the human optic nerve. Invest Ophthalmol Vis Sci 1990;31:736-44.

30 Vogel KG, Paulsson M, Heinegard D. Specific inhibition of type I and type II collagen fibrillogenesis by the low molecular mass proteoglycan of tendon. Biochem $\mathcal{7}$ 1984;223:587-97.

31 Ruoslahti E. Proteoglycans in cell regulation. 7 Cell Biol 1989;264:13369-72.

32 Parry DAD, Craig AS. Growth and development of collagen fibrils in connective tissue. In: Ruggeri A, Motta PM, eds. Ultrastructure of the connective tissue matrix. Boston: Martinus Nijhoff, 1984:34-63.

33 Quigley HA. Childhood glaucoma: results with trabeculotomy and study of reversible cupping. Ophthalmology 1982;89:219-26.

34 Albon J, Purslow PP, Karwatowski WSS. Age-related compliance of the lamina cribrosa in human eyes. $f$ Biomech 1994;27:823.

35 Hernandez MR, Igoe F, Neufeld AH. Cell culture of the human lamina cribrosa. Invest Ophthalmol Vis Sci 1988;29: $78-89$.

36 Yang JL, Neufeld AH, Zorn MB, et al. Collagen type I mRNA levels in cultured human lamina cribrosa cells: effects of elevated hydrostatic pressure. Exp Eye Res 1993;56:567-74

37 Carbonetto S. The extracellular matrix of the nervous systems. Trends Neurosci 1984;7:382-7.

38 Elkington AR, Inman CBE, Steart PV, et al. The structure of the lamina cribrosa of the human eye: an immunohistochemical and electron microscopical study Eye 1990;4:4257.

39 Juurlink BHJ, Hertz L. Astrocytes. In: Boulton A, Baker G, Walz W, eds. Neuromethods. Vol 23. Practical cell culture techniques. Totawa, NJ: Humana Press, 1992:269-321.

40 Ben Ami Y, von der Mark K, Franzen A, et al. Immunohistochemical studie sof the extracellular matrix in Immunohistochemical studie sof the extracellular matrix in and concollagenous proteins. Am $\mathcal{F}$ Anat 1991;190:157-66.

41 Carter G, Sloane P, Aaron JE. Immunolocalisation of collagen types I and III, tenascin, and fibronectin in intramemgen types I and III, tenascin, and fibronectin in intrame
branous bone. $\mathcal{F}$ Histochem Cytochem 1992;39:599-606.

42 Vitarello-Zuccarello L, Garbelli R, Dal Poxxo Rossi V. Immunocytochemical localisation of collagen types I, III, IV, and fibronectin in the human dermis: modifications with ageing. Cell Tissue Res 1992;268:505-11.

43 Lorimier P, Mezin P, Labat Moleur F, et al. Ultrastructural localisation of the major components of the extracellular matrix in normal rat nerve. $\mathcal{F}$ Histochem Cytochem 1992;40: $859-68$

44 Sandberg LB. Elastin structure in health and disease. Int Rev Conn Tissue Res 1976;7:159-210. 